\title{
KEKONVERGENAN METODE PANGKAT UNTUK GESERAN TETAP DAN GESERAN SIKLIK
}

\author{
SISKA ZALNI IRIANTI \\ Program Studi Matematika, \\ Fakultas Matematika dan Ilmu Pengetahuan Alam, Universitas Andalas, \\ Kampus UNAND Limau Manis Padang, Indonesia, \\ email : siskazalni@gmail.com
}

\begin{abstract}
Abstrak. Metode pangkat digunakan untuk menghitung pasangan eigen dominan secara numerik. Pada paper ini dibahas penurunan metode pangkat tanpa geseran dan dengan geseran, serta analisis kekonvergenan dari metode pangkat untuk geseran tetap dan geseran siklik beserta contoh ilustrasinya.

Kata Kunci: Metode pangkat, kekonvergenan, pasangan eigen dominan, geseran tetap, geseran siklik
\end{abstract}

\section{Pendahuluan}

Metode pangkat merupakan metode iteratif numerik dalam menentukan nilai eigen dominan dari suatu matriks, yaitu nilai eigen yang mutlaknya lebih besar daripada nilai mutlak nilai eigen lainnya [3]. Rumus iterasi metode pangkat dengan vektor tebakan awal $\mathbf{v}^{(0)}$ diberikan oleh

$$
\mathbf{v}^{(k+1)}=(A+p I) \mathbf{v}^{(k)},
$$

dimana $A$ adalah matriks berukuran $N \times N, I$ matriks identitas, dan $p$ adalah parameter geseran. Bila $p=0$, iterasi (1.1) akan konvergen ke vektor eigen yang bersesuaian dengan nilai eigen dominan, sedangkan $p$ yang tak nol digunakan untuk mempercepat kekonvergenan ke nilai eigen dominan atau untuk menggeser kekonvergenan ke nilai eigen lain yang diinginkan

Hal terpenting dari metode pangkat terletak pada penentuan nilai eigen dominan dari matriks yang berukuran besar [1]. Matriks tersebut misalnya diperoleh dari aproksimasi beda hingga pada persamaan diferensial parsial multidimensi. Semakin besar ukuran matriks, maka semakin berat beban komputasi yang diperlukan metode pangkat dalam menghitung nilai eigen dominan. Untuk alasan ini, banyak peneliti di bidang numerik yang berfokus pada kajian tentang peningkatan laju kekonvergenan metode pangkat $[1,3]$.

Sebagaimana yang telah disebutkan sebelumnya, parameter geseran dapat meningkatkan laju kekonvergenan. Namun belum ada metode sistematik untuk memilih parameter geseran yang dapat mempercepat laju kekonvergenan dengan optimal. Langkah yang biasa digunakan adalah mencoba suatu parameter geseran (disebut geseran tetap) yang membuat metode pangkat konvergen dengan lebih cepat. 
Pada paper ini akan ditinjau suatu cara alternatif dalam mempercepat kekonvergenan metode pangkat, yaitu dengan memperkenalkan suatu barisan siklik dari parameter-parameter geseran (disingkat geseran siklik). Ide ini dikembangkan pertama kali oleh Craig dan Sneyd [2] dan paper ini mengeksplorasi kembali kajian yang mereka lakukan.

\section{Landasan Teori}

\subsection{Vektor Eigen dan Nilai Eigen}

Definisi 2.1. [5] Jika A adalah matriks $N \times N$, maka vektor taknol $\mathbf{v}$ di $\mathbb{R}^{N}$ dinamakan vektor eigen dari A jika Av adalah kelipatan skalar dari $\mathbf{v}$; yakni,

$$
A \mathbf{v}=\lambda \mathbf{v}
$$

untuk suatu skalar $\lambda$. Skalar $\lambda$ dinamakan nilai eigen dari $A$ dan $\mathbf{v}$ dikatakan vektor eigen yang bersesuaian dengan $\lambda$. Pasangan $(\lambda, \mathbf{v})$ disebut sebagai pasangan eigen dari matriks $A$.

Definisi 2.2. [3] Jika $\lambda_{1}$ adalah nilai eigen dari matriks A yang nilai mutlaknya lebih besar dari nilai mutlak nilai eigen lainnya, maka $\lambda_{1}$ disebut nilai eigen dominan. Vektor eigen $\mathbf{v}_{\mathbf{1}}$ yang bersesuaian dengan $\lambda_{1}$ disebut vektor eigen dominan. Pasangan $\left(\lambda_{1}, \mathbf{v}_{\mathbf{1}}\right)$ disebut sebagai pasangan eigen dominan dari matriks $A$.

Definisi 2.3. [3] Vektor eigen $\mathbf{v}$ dikatakan ternormalkan jika elemen yang paling besar pada vektor $\mathbf{v}$ adalah 1 .

Teorema 2.4. [3] Misalkan ( $\lambda, \mathbf{v})$ adalah suatu pasangan eigen dari matriks $A$. Jika $p$ suatu konstanta sebarang, maka $(\lambda+p, \mathbf{v})$ adalah suatu pasangan eigen dari matriks $A+p I$.

Selanjutnya pandang matriks tridiagonal dalam bentuk

$$
A=\left[\begin{array}{rrrrr}
a & b & & \\
c & a & b & \\
& c & \ddots & \ddots & \\
& \ddots & a & b \\
& & c & a
\end{array}\right] \in \mathbb{R}^{N \times N},
$$

Nilai eigen dari matriks tridiagonal (2.2) diberikan oleh [4]

$$
\lambda_{s}=a+2 \sqrt{b c} \cos \left(\frac{\pi s}{N+1}\right), s=1, \cdots, N .
$$

\subsection{Polinomial Chebyshev}

Definisi 2.5. [6] Polinomial Chebyshev $T_{N}(x)$ berderajat $N$ didefinisikan sebagai

$$
T_{N}(x)=\cos N \theta \text { dengan } x=\cos \theta .
$$

Berikut diberikan sifat-sifat dari polinomial Chebyshev. 
Sifat 1. [3] Koefisien dari $x_{N}$ di $T_{N}(x)$ adalah $2^{N-1}$ ketika $N \geqslant 1$.

Sifat 2. [3] Misalkan $M$ bilangan bulat nonnegatif. Ketika $N=2 M, T_{2 M}(x)$ adalah fungsi genap, yaitu

$$
T_{2 M}(-x)=T_{2 M}(x) .
$$

Ketika $N=2 M+1, T_{2 M+1}(x)$ adalah fungsi ganjil, yaitu

$$
T_{2 M+1}(-x)=-T_{2 M+1}(x) .
$$

Sifat 3. [3] $T_{N}(x)$ mempunyai $N$ akar berbeda yang berada pada interval $[-1,1]$, yaitu :

$$
x_{k}=\cos \left(\frac{(2 k-1) \pi}{2 N}\right) \text { untuk } k=1,2, \cdots, N .
$$

Persamaan ini dinamakan absis Chebyshev.

\section{Metode Pangkat}

Dalam paper ini akan dijelaskan terlebih dahulu penurunan metode pangkat.

Teorema 3.1. [3] Asumsikan matriks $A$ yang berukuran $N \times N$ mempunyai $N$ nilai eigen $\lambda_{1}, \lambda_{2}, \cdots, \lambda_{N}$ yang berbeda dan terurut sebagai berikut:

$$
\left|\lambda_{1}\right|>\left|\lambda_{2}\right| \geq\left|\lambda_{3}\right| \geq \cdots \geq\left|\lambda_{N}\right| \text {. }
$$

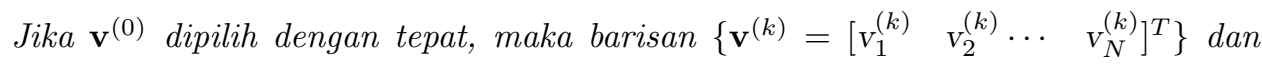
$\left\{c_{k}\right\}$ yang dibangkitkan secara rekursif oleh

$$
\mathbf{y}^{(k)}=A \mathbf{v}^{(k)}
$$

dan

$$
\mathbf{v}^{(k+1)}=\frac{1}{c_{k+1}} \mathbf{y}^{(k)}
$$

dimana

$$
c_{k+1}=v_{j}^{(k)} d a n v_{j}^{(k)}=\max _{1 \leq i \leq N}\left\{\left|v_{i}^{(k)}\right|\right\},
$$

masing-masing akan konvergen ke vektor eigen dominan $\mathbf{v}_{1}$ dan nilai eigen dominan $\lambda_{1}$, yaitu

$$
\lim _{k \longrightarrow \infty} \mathbf{v}^{(k)}=\mathbf{v}_{1} \text { dan } \lim _{k \rightarrow \infty} c_{k}=\lambda_{1} .
$$

Penurunan metode pangkat dengan geseran diberikan dalam teorema berikut.

Teorema 3.2. [3] Misalkan matriks A mempunyai nilai-nilai eigen yang berbeda $\lambda_{1}, \lambda_{2}, \cdots, \lambda_{N}$ dan tinjau nilai eigen $\lambda_{j}$. Maka suatu konstanta $p$ dapat dipilih sedemikian sehingga $\mu_{1}=\lambda_{j}+p$ adalah nilai eigen dominan dari $A+p I$. Selanjut-

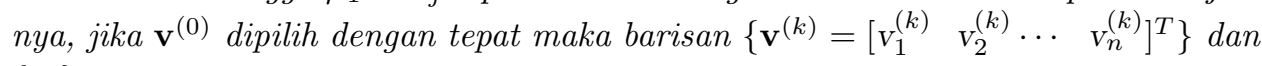
$\left\{c_{k}\right\}$ yang dibangkitkan secara rekursif oleh

$$
\mathbf{y}^{(k)}=(A+p I) \mathbf{v}^{(k)}
$$


dan

$$
\mathbf{v}^{(k+1)}=\frac{1}{c_{k+1}} \mathbf{y}^{(k)}
$$

dimana

$$
c_{k+1}=v_{j}^{(k)} \operatorname{dan} v_{j}^{(k)}=\max _{1 \leq i \leq n}\left\{\left|v_{i}^{(k)}\right|\right\},
$$

masing-masing akan konvergen ke vektor eigen dominan $\mathbf{v}_{j}$ dan nilai eigen dominan $\mu_{1}$ dari matriks $A+p I$. Selanjutnya, nilai eigen yang bersesuaian dari matriks $A$ diberikan oleh

$$
\lambda_{j}=\mu_{1}-\alpha .
$$

Kekonvergenan untuk metode pangkat dengan geseran dijelaskan pada bab selanjutnya.

\section{Kekonvergenan Metode Pangkat}

\subsection{Kekonvergenan untuk Geseran Tetap}

Misalkan matriks $A$ yang berukuran $N \times N$ mempunyai $N$ nilai eigen $\lambda_{1}, \lambda_{2}, \cdots, \lambda_{N}$ yang berbeda dan terurut sebagai berikut :

$$
\left|\lambda_{1}\right|>\left|\lambda_{2}\right| \geq\left|\lambda_{3}\right| \geq \cdots \geq\left|\lambda_{N}\right| \text {. }
$$

Selanjutnya misalkan $\mathbf{v}_{j}, j=1,2, \cdots, N$, adalah vektor eigen yang bersesuaian dengan nilai eigen $\lambda_{j}$. Jelas bahwa $\left(\lambda_{1}, \mathbf{v}_{1}\right)$ adalah pasangan eigen dominan.

Berdasarkan asumsi di atas, maka vektor sebarang $\mathbf{v}^{(0)}$ dapat dinyatakan sebagai kombinasi linier dari vektor-vektor eigen dari $A$, yaitu

$$
\mathbf{v}^{(0)}=\sum_{j=1}^{N} b_{i} \mathbf{v}_{i},
$$

dengan $b_{i}, i=1,2, \cdots, N$ suatu skalar sebarang. Dengan menggunakan persamaan (3.2) dan (3.3) diperoleh

$$
\begin{aligned}
\mathbf{v}^{(1)} & =\frac{b_{1}}{c_{1} c_{2} \cdots c_{k-1} c_{k}} \lambda_{1}^{k} \mathbf{v}_{1}+\frac{b_{2}}{c_{1} c_{2} \cdots c_{k-1} c_{k}} \lambda_{2}^{k} \mathbf{v}_{2}+\cdots+\frac{b_{N}}{c_{1} c_{2} \cdots c_{k-1} c_{k}} \lambda_{N}^{k} \mathbf{v}_{N} . \\
\mathbf{v}^{(2)} & =\frac{b_{1}}{c_{1} c_{2}} \lambda_{1}^{2} \mathbf{v}_{1}+\frac{b_{2}}{c_{1} c_{2}} \lambda_{2}^{2} \mathbf{v}_{2}+\cdots+\frac{b_{N}}{c_{1} c_{2}} \lambda_{N}^{2} \mathbf{v}_{N}, \\
& \vdots \\
\mathbf{v}^{(k)} & =\frac{b_{1}}{c_{1} c_{2} \cdots c_{k-1} c_{k}} \lambda_{1}^{k} \mathbf{v}_{1}+\frac{b_{2}}{c_{1} c_{2} \cdots c_{k-1} c_{k}} \lambda_{2}^{k} \mathbf{v}_{2}+\cdots+\frac{b_{N}}{c_{1} c_{2} \cdots c_{k-1} c_{k}} \lambda_{N}^{k} \mathbf{v}_{N} .
\end{aligned}
$$

Dengan memisalkan $\alpha_{j}=\frac{b_{j}}{c_{1} c_{2} \cdots c_{k-1} c_{k}}, j=1,2, \cdots N$, maka persamaan (4.3) dapat ditulis

$$
\mathbf{v}^{(k)}=\sum_{j=1}^{N} \alpha_{j} \lambda_{j}^{k} \mathbf{v}_{j} .
$$


Jika matriks $A$ diganti menjadi matriks $A+p I$, dengan $p$ suatu konstanta, maka berdasarkan Teorema 2.4 dan Teorema 3.2 , persamaan (4.4) menjadi

$$
\mathbf{v}^{(k)}=\sum_{j=1}^{N} \alpha_{j}\left(\lambda_{j}+p\right)^{k} \mathbf{v}_{j},
$$

yang merupakan rumus iterasi metode pangkat dengan geseran tetap $p$. Jelas bahwa iterasi (4.5) konvergen ke vektor eigen di mana $\left|\lambda_{i}+p\right|$ maksimum. Jika $p$ dipilih sedemikian sehingga

$$
\left|\lambda_{1}+p\right|>\left|\lambda_{N}+p\right| \text { atau }\left|\lambda_{1}+p\right|>\left|\lambda_{2}+p\right|,
$$

maka iterasi (4.5) berdasarkan teorema 3.1 konvergen ke vektor eigen $\mathbf{v}_{1}$ (asumsikan $\left.\alpha_{1} \neq 0\right)$. Pada kasus ini laju kekonvergenan ditentukan oleh rasio

$$
q=\max \left\{\left|\frac{\lambda_{2}+p}{\lambda_{1}+p}\right|,\left|\frac{\lambda_{N}+p}{\lambda_{1}+p}\right|\right\} .
$$

Jika

$$
\left|\lambda_{2}+p\right|=\left|\lambda_{N}+p\right| \text { dan } \lambda_{2} \neq \lambda_{N}
$$

maka berlaku

$$
p=-\frac{1}{2}\left(\lambda_{2}+\lambda_{N}\right) .
$$

Dengan menggunakan $p$ pada persamaan (4.8), maka laju kekonvergenan menjadi optimal dan rasio kekonvergenan menjadi

$$
q=\left|\frac{\lambda_{2}-\lambda_{N}}{2 \lambda_{1}-\left(\lambda_{2}+\lambda_{N}\right)}\right|
$$

Sebagai contoh, misalkan suatu matriks $A$ yang berukuran $6 \times 6$ mempunyai nilai eigen $\lambda_{j}=21-j, j=1,2, \cdots, 6$. Karena $\lambda_{1}$ adalah nilai eigen dominan, maka dengan menggunakan metode pangkat tanpa geseran $(p=0)$, diperoleh vektor eigen yang konvergen ke vektor eigen $\mathbf{v}_{1}$, dengan rasio laju kekonvergenan $q=\frac{\left|\lambda_{2}\right|}{\left|\lambda_{1}\right|}=\frac{19}{20}$. Jika diambil $p=17$, maka nilai-nilai eigen menjadi $3, \pm 2, \pm 1,0$ dan iterasi vektor eigen tetap konvergen ke $\mathbf{v}_{1}$ karena nilai eigen $\lambda_{1}+p$ dominan. Rasio laju kekonvergenannya sekarang diberikan oleh $q=\frac{\left|\lambda_{2}+p\right|}{\left|\lambda_{1}+p\right|}=\frac{2}{3}$. Contoh ini memperlihatkan bahwa geseran tetap $p$ dapat mempercepat laju kekonvergenan metode pangkat.

Keterbatasan dari metode pangkat dengan geseran tetap dapat diilustrasikan dengan meninjau matriks tridiagonal simetri berukuran $N \times N$ berikut ini :

$$
A(r)=\left[\begin{array}{cccccc}
1-2 r & r & 0 & \cdots & 0 & 0 \\
r & 1-2 r & r & \cdots & 0 & 0 \\
0 & r & 1-2 r & \cdots & 0 & 0 \\
\vdots & \vdots & \ddots & \ddots & \vdots & \vdots \\
0 & 0 & 0 & \cdots & 1-2 r & r \\
0 & 0 & 0 & \cdots & r & 1-2 r
\end{array}\right]
$$

Berdasarkan persamaan 2.3, nilai eigen dari matriks (4.10) adalah

$$
\lambda_{j}=1-4 r \sin ^{2}\left(\frac{j \pi}{2(N+1)}\right) .
$$


Namun kekonvergenan dari metode pangkat dengan geseran tetap tidak memberikan hasil yang signifikan ketika sekumpulan nilai eigen berada di sekitar $\lambda_{1} \approx 1$ untuk $N$ yang besar. Sebagai contoh, untuk $N=90$ dan $r=0.4$ diperoleh

$$
\lambda_{1}=0.99952, \lambda_{2}=0.99809, \lambda_{N}=-0.59952,
$$

dan geseran optimal adalah

$$
p=-0.199285 \text {, }
$$

sehingga rasio kekonvergenannya diberikan oleh

$$
q=0.99821 .
$$

Hasil ini hanyalah sebuah peningkatan kecil dibandingkan menggunakan $p=0$ yang memiliki rasio kekonvergenan $q=\lambda_{2} / \lambda_{1}=0.99809 / 0.99952=0.99857$.

\subsection{Kekonvergenan untuk Geseran Siklik}

Pandang suatu pasangan eigen $(\lambda, \mathbf{v})$ dari suatu matriks. Untuk mempercepat laju kekonvergenan metode pangkat, Craig dan Sneyd [2] memperkenalkan barisan $K$ siklik yang terdiri dari geseran-geseran $p_{1}, p_{2}, \cdots, p_{K}$. Faktor amplifikasi untuk sebarang nilai eigen $\lambda$ dalam satu periode siklik adalah

$$
\gamma_{K}(\lambda)=\prod_{k=1}^{K}\left(\lambda+p_{k}\right) .
$$

Selanjutnya ingin dicari nilai $p_{k}$ yang akan memaksimumkan nilai $\left|\gamma_{K}\left(\lambda_{1}\right)\right|$ atas nilai $\left|\gamma_{K}\left(\lambda_{j}\right)\right|, j=2, \cdots, N$. Karena $\gamma_{K}$ adalah sebuah polinomial berderajat $K$ dalam $\lambda$, maka masalahnya adalah bagaimana membangun suatu polinomial yang memiliki sifat-sifat yang diinginkan. Solusinya diberikan oleh polinomial Chebyshev $T_{K}(x)$, yang didefinisikan oleh [2]

$$
\begin{gathered}
T_{K}(x)= \begin{cases}\cos K \theta, & x=\cos \theta, \quad 0 \leq x \leq 1 ; \\
\cosh K \theta, \quad x=\cosh \theta, \quad x>1\end{cases} \\
T_{K}(-x)=(-1)^{K} T_{K}(x) .
\end{gathered}
$$

Untuk $K$ genap

$$
\begin{aligned}
T_{K}(x) & =T_{K}(-x) \\
& = \begin{cases}\cos K \theta, & x=\cos \theta, \quad-1 \leq x \leq 0 ; \\
\cosh K \theta, & x=\cosh \theta, \quad x<-1 ;\end{cases}
\end{aligned}
$$

Untuk $K$ ganjil

$$
\begin{aligned}
T_{K}(-x) & =-T_{K}(x) \\
& = \begin{cases}-\cos K \theta, \quad x=\cos \theta, \quad-1 \leq x \leq 0 ; \\
-\cosh K \theta, \quad x=\cosh \theta, \quad x<-1 ;\end{cases}
\end{aligned}
$$

Fungsi (4.14) dan (4.15) mempunyai sifat bahwa untuk $|x| \leq 1$, kurvanya berisolasi di antara \pm 1 , sedangkan untuk $|x|>1$, kurvanya meningkat dengan tajam untuk 
kasus $K=6)$. Dengan demikian akar-akar $\beta_{j}$ dari $T_{K}(x)$ semuanya berada pada interval $-1 \leq x \leq 1$. Akar-akar $\beta_{j}$ diperoleh sebagai berikut :

$$
x=\beta_{j}=\cos \left[\left(\frac{2 j-1}{2 K}\right) \pi\right], \quad j=1,2, \cdots, K .
$$

Jika digunakan transformasi

$$
x=\frac{\lambda-c}{h}, \quad c=\frac{1}{2}\left(\lambda_{a}+\lambda_{b}\right), \quad h=\frac{1}{2}\left(\lambda_{b}-\lambda_{a}\right),
$$

maka interval $\lambda_{a} \leq \lambda \leq \lambda_{b}$ dipetakan ke $-1 \leq x \leq 1$. Interval $\left[\lambda_{a}, \lambda_{b}\right]$ disebut "killing interval" karena nilai-nilai eigen dalam interval ini secara umum akan saling menghilangkan ketika proses iterasi berjalan. Dengan memilih

$$
p_{i}=-\beta_{i} h-c,
$$

maka

$$
\gamma_{K}(\lambda)=\frac{h^{K} T_{K}(x)}{2^{K-1}}
$$

Konstanta $2^{K-1}$ pada persamaan (4.23) muncul karena koefisien dari $x^{K}$ di $T_{K}(x)$ adalah $2^{K-1}$ (lihat sifat 1 ). Dengan demikian untuk menentukan nilai eigen dominan $\lambda_{1}$ dipilih "killing interval" $\left[\lambda_{N}, \lambda_{2}\right]$. Laju kekonvergenan dalam satu periode siklik diberikan oleh

$$
q^{K}=\frac{\max \left\{\left|T_{K}\left(x_{j}\right)\right|, j=2,3, \cdots, K\right\}}{\left|T_{K}\left(x_{1}\right)\right|},
$$

dimana $x_{j}=\left(\lambda_{j}-c\right) / h$. Karena $\left|T_{K}\left(x_{j}\right)\right| \leq 1$ (dengan kesamaan terjadi ketika $j=2$ dan $j=N)$, maka

$$
q^{K}=\frac{1}{\left|T_{K}\left(x_{1}\right)\right|} .
$$

Pemercepatan kekonvergenan metode pangkat untuk geseran siklik ini dapat diilustrasikan dengan memandang kembali matriks tridiagonal simetri (4.10) yang mempunyai nilai eigen $\lambda_{1}, \lambda_{2}$, dan $\lambda_{N}$ seperti yang diberikan pada (4.12).

Untuk kasus ini diperoleh

$$
\begin{gathered}
c=0.199285, \\
h=0.798805, \\
x_{1}=-1.0017901741, \\
\theta=3.1416-0.0598 i .
\end{gathered}
$$

Untuk $K=1$ diperoleh

$$
T_{1}\left(x_{1}\right)=-1.0018
$$

sehingga rasio kekonvergenannya adalah

$$
q=0.9982
$$


Untuk $K=10$ diperoleh

$$
T_{10}\left(x_{1}\right)=1.1842
$$

sehingga rasio kekonvergenannya adalah

$$
q=0.9832
$$

Untuk $K=50$ diperoleh

$$
T_{50}\left(x_{1}\right)=9.9814
$$

sehingga rasio kekonvergenannya adalah

$$
q=0.9550
$$

Dari hasil di atas dapat dilihat bahwa kekonvergenan dengan geseran siklik pada contoh ini semakin cepat ketika nilai $K$ semakin besar.

\section{Kesimpulan}

Pada tugas akhir ini telah dibahas penurunan metode pangkat tanpa dan dengan parameter geseran dalam menghitung nilai eigen dominan suatu matriks secara numerik. Misalkan suatu matriks $A$ berukuran $N \times N$ mempunyai nilai eigen yang terurut sebagai berikut:

$$
\left|\lambda_{1}\right|>\left|\lambda_{2}\right| \geq\left|\lambda_{3}\right| \geq \cdots \geq\left|\lambda_{N}\right|
$$

Tinjau parameter geseran tetap $p$ sedemikian sehingga berlaku

$$
\left|\lambda_{1}+p\right|>\left|\lambda_{N}+p\right| \text { atau }\left|\lambda_{1}+p\right|>\left|\lambda_{2}+p\right| \text {. }
$$

Laju kekonvergenan optimal dari metode pangkat dengan geseran $p$ ini ditentukan oleh rasio

$$
q=\left|\frac{\lambda_{2}-\lambda_{N}}{2 \lambda_{1}-\left(\lambda_{2}+\lambda_{N}\right)}\right|
$$

Laju kekonvergenan dengan menggunakan geseran tetap memiliki keterbatasan ketika sekumpulan nilai eigen berada di sekitar nilai eigen dominan. Untuk mengatasi hal tersebut, diperkenalkan barisan $K$ - siklik dari parameter-parameter geseran $p_{1}, p_{2}, \cdots, p_{K}$. Laju kekonvergenan dari metode pangkat dengan geseran siklik ini ditentukan oleh rasio

$$
q^{K}=\frac{1}{\left|T_{K}\left(x_{1}\right)\right|},
$$

dimana $T_{K}\left(x_{1}\right)$ adalah polinomial Chebyshev berderajat $K$ dengan $x_{1}=\frac{\lambda_{1}-c}{h}$, $c=\frac{1}{2}\left(\lambda_{N}+\lambda_{2}\right)$, dan $h=\frac{1}{2}\left(\lambda_{N}-\lambda_{2}\right)$.

\section{Ucapan Terima kasih}

Penulis mengucapkan terima kasih kepada Bapak Dr. Mahdhivan Syafwan, Ibu Dr. Yanita, Bapak Dr. Dodi Devianto, Bapak Dr. Jenizon, dan Ibu Radiatul Husna, M.Si yang telah memberikan masukan dan saran sehingga paper ini dapat diselesaikan dengan baik. 
92 Siska Zalni Irianti

\section{Daftar Pustaka}

[1] Wilkinson, J.H. (1965). The Algebraic Eigenvalue Problem. Clarendon Press, Oxford.

[2] Craig, I. J. D. dan A. D. Sneyd. (1989). The acceleration of matrix power method by cyclic variations of the shift parameter, Computer Math. Applic Vol. 17, pp. 1149-1159.

[3] Mathews, John H. (1999). Numerical Methods using Matlab. Third Edition. Prentice Hall, California.

[4] Smith, G.D.(1985). Numerical Solution of Partial Differential Equations. Third Edition. Clarendon Press, Oxford.

[5] Anton, Howard dan Chris Rorres. (2005). Aljabar Linier Elementer. Versi Aplikasi Jilid 1 Edisi Delapan. Erlangga, Jakarta.

[6] Mason, J. C. dan D.C. Handscomb. (2003). Chebyshev Polynomials. A CRC Press Company, Boca Raton London New York Washington,D.C. 